\title{
Jogos de poder nas dobras do legal e do ilegal: anotações de um percurso de pesquisa
}

\section{Games of Power between the lines of the legal and the illegal: notes of a research}

Vera Telles*

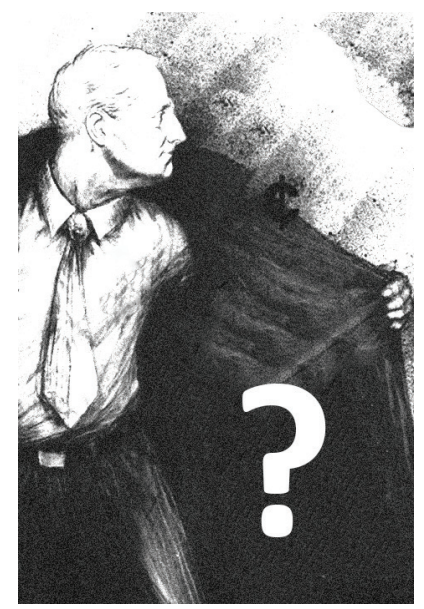

Resumo: O texto volta-se para os jogos de poder que se processam justamente nas dobras do legal e ilegal, formal e informal. Se é verdade que a transitividade de pessoas, bens e mercadorias nas fronteiras incertas do legal e ilegal, formal e informal, constitui um fenômeno transversal da experiência contemporânea e está no cerne dos processos de mundialização, argumenta-se que nem por isso a passagem de um lado a outro dessas fronteiras porosas é coisa simples. A questão que se procura trabalhar nesse texto é que esses campos de força oferecem uma via de entrada para entender o lugar e o papel do Estado nos ordenamentos sociais, pondo em foco os modos de operação das forças da lei e da ordem em contextos situados, sob a perspectiva do que alguns autores vêm propondo nos termos de uma "antropologia do Estado".

Palavras-chave: Práticas urbanas. Ilegalismos. Jogos de poder. Antropologia do Estado.

\begin{abstract}
The article is about the games of power that exist between the lines of the legal and the illegal, the formal and the informal. If it is true that the transitivity of people, goods and merchandise on the uncertain borders between the legal and the illegal, the formal and the informal is a transversal phenomenon of the contemporary experience and that it is in the center of the globalization processes, that does not mean the passage from one side to the other one of those porous borders is simple. What we discuss in this article is that those fields of force offer an entry to understand the importance and the role of the State in the social planning, focusing the way the forces of law and order operate in situated contexts, under the view of what some authors have been calling a "state anthropology".
\end{abstract}

Keywords: Urban practices. Illegalism. Games of Power. State anthropology.

* Professora do Departamento de Sociologia da Universidade de São Paulo, São Paulo, Brasil. Pesquisadora e vice-coordenadora do Laboratório de Pesquisa Social (USP).E-mail: tellesvs@uol.com.br; www.veratelles.net. 


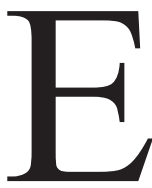

ste texto trata dos jogos de poder inscritos na trama dos ilegalismos que se alojam, hoje, no cerne da vida e da economia urbana, aqui e alhures. O ponto de partida do que se pretende discutir diz respeito a um mundo urbano alterado e redefinido por formas contemporâneas de produção e circulação de riquezas, que ativam os circuitos da chamada economia informal, que mobilizam as várias figuras do trabalho precário e se processam nas fronteiras incertas do formal e informal, legal e ilegal, também o ilícito. Tomo como referência empírica a cidade de São Paulo, tendo em mira processos transnacionais que colocam essas reconfigurações em ressonância com o que vem ocorrendo em outros lugares. E é isso que coloca a questão de se entender o modo como esses deslocamentos e essas reconfigurações se processam nos circuitos urbanos de circulação de riquezas e as relações de poder inscritas em seus pontos de interseção.

Essas são questões que tentei trabalhar em textos anteriores, apoiando-me nos percursos de uma pesquisa já de muitos anos em duas frentes articuladas de investigação: os mercados de consumo popular no centro da cidade e o varejo da droga em um bairro da periferia de São Paulo. De forte conteúdo etnográfico, essas pesquisas nos permitiram seguir e descrever essa transitividade de pessoas, bens e mercadorias entre o formal e o informal, o legal e ilegal, o lícito e o ilícito. Mais ainda, o mais importante: essas pesquisas nos permitiram flagrar as fricções engendradas nas passagens dessas fronteiras porosas. Fronteiras porosas, mas não vazias: os espaços não são lisos, e sim estriados, para usar os termos de Deleuze e Guatarri, e é justamente nesses estriamentos que se dão os agenciamentos políticos que condicionam (permitem, bloqueiam, filtram, direcionam) essa circulação de pessoas, bens e mercadorias nos espaços urbanos.

Em um primeiro momento, essas questões se apresentaram nas filigranas dos percursos, que tratamos de reconstituir, de trabalhadores que lançavam mão de forma descontínua e intermitente das oportunidades legais e ilegais que coexistem e se superpõem nos mercados de trabalho: as "mobilidades laterais" entre o formal e o informal, legal e ilegal, para usar os termos de Ruggiero e South (1997) ao descreverem situações parecidas, alojadas, hoje, no coração das economias urbanas também dos países do Norte. Ao seguirmos esses percursos, chamava-nos a atenção o modo como os indivíduos transitavam (e transitam) nas fronteiras porosas do legal e do ilegal, fazendo uso dos códigos e repertórios de ambos os lados. Sobretudo, chamava-nos a atenção o exercício de algo como uma "arte do contornamento" dos constrangimentos, ameaças e riscos (também riscos de morte) inscritos nesses pontos de passagem: o pesado jogo de chantagem e extorsão de fiscais de 
prefeitura e das forças da ordem; a violência da polícia sempre presente nesses percursos; também os controles mafiosos de territórios e pontos de venda; bem como a eventualidade de algum desarranjo nos acertos instáveis com os empresários do ilícito (não apenas dos negócios da droga). "Ardis de uma inteligência prática”, essa noção trabalhada por Vernant e Detienne (1974) nos foi especialmente valiosa para entender o modo como os indivíduos lidam com as circunstâncias movediças nas fronteiras do legal-ilegal e fazem, a cada situação, a negociação dos "critérios de plausibilidade moral" de suas escolhas, para usar os termos de Ruggiero e South ao caracterizar a lógica da "economia de bazar" que hoje se instala no coração das economias urbanas: nos termos nativos, os critérios do "certo" e do "errado" — "é preciso andar pelo certo" é a expressão que se ouve nesses lugares. Também: o modo como, nesses pontos de friç̧ão, os indivíduos negociam os parâmetros do aceitável e os limites do tolerável nos jogos de poder que se estruturam nesse seu encontro com as injunções da lei e da ordem (Telles e Hirata, 2010; Telles, 2010a; Hirata, 2010).

Esses agenciamentos práticos nas dobras do legal e ilegal nos pareciam (e nos parecem) estratégicos para entender os ordenamentos sociais que se processam nos circuitos dos mercados informais e ilegais da cidade. Foi daí que partimos, desdobrando nossas questões de pesquisa na medida em que tratamos de entender a mecânica desses agenciamentos. O que poderia ser visto como versão atualizada da "viração" associada à cultura popular ou à "dialética da malandragem", para lembrar aqui o texto famoso de Antonio Candido, passava a ganhar outra fatura. Muito longe das visões algo pacificadas do mundo social veiculadas por essas expressões, essas dobraduras do legal e ilegal pareciam circunscrever jogos de poder e relações de força, campos de tensão e de conflito, que precisariam ser bem entendidos. Certamente, algo constitutivo da "economia de bazar," para reter os termos de Ruggiero e South e que, no caso de nossas cidades, carrega uma história de longa data, acompanhando os percursos dos desde sempre expansivos mercados informais, sempre próximos e tangentes aos mercados ilícitos, entrelaçados, ambos, nos tempos, fatos e circunstâncias da história urbana. Mas esses agenciamentos nos pareciam, sobretudo, estratégicos para entender as inflexões recentes desses mercados por conta de suas conexões com os circuitos ilegais de economias transnacionais. No coração da modernidade globalizada da(s) cidade(s), esses mercados mudaram de escala e ganharam outras configurações, acompanhando ritmos e evoluções aceleradíssimos da abertura dos mercados e expansão de circuitos transnacionais por onde circulam bens e mercadorias, transpassando fronteiras, regula- 
mentações, restrições nacionais, de que o fenômeno maciço do contrabando e falsificações é o registro visível nos centros urbanos dos países a norte e a sul, leste e oeste do planeta. Em São Paulo, no mesmo período e mais intensamente a partir dos anos 2000, o mercado varejista de droga se estruturou de forma mais ampla e mais articuladas do que em décadas passadas. Mas isso também significa dizer que a expansão da economia da droga e suas capilaridades no mundo urbano acompanharam a aceleração dos fluxos de circulação de riquezas em uma cidade que, no correr desses anos, também se firmou e se confirmou na potência econômica e financeira própria de uma cidade globalizada (Telles, 2010b).

O fato é que essa ampla circulação de bens, produtos e populações que transitam nesses mercados depende, em grande medida, dos agenciamentos políticos que se fazem justamente nas dobras do legal-ilegal, formal-informal: corrupção, mercados de proteção e práticas de extorsão que variam conforme circunstâncias, contextos e microconjuturas políticas e, sobretudo, dos níveis de tolerância ou incriminação que pesam sobre essas atividades. O que, em um primeiro momento, aparecia nas filigranas das "histórias minúsculas" que recolhíamos em nosso trabalho de campo ganhava outra envergadura e delineava a face política desses mercados. E era isso que nos parecia (e nos parece) importante de ser bem entendido. Aqui, nesse registro, noção de mercadoria política proposta por Michel Misse (2006) foi (e é) de especial importância para conferir inteligibilidade a esses agenciamentos nas dobras do legal e do ilegal. É uma noção que opera efetivamente como um operador analítico: desativa a categoria moral-normativa de corrupção, desloca a discussão do campo da avaliação moral dessas práticas e define um espaço conceitual a partir do qual é possível deslindar a dinâmica política desses mercados, melhor dizendo: o lugar do Estado na formação e estruturação desses mercados. O que está aqui sendo formulado como dobras do legal e ilegal qualifica-se e ganha em precisão. Nos termos de Misse, trata-se da articulação desses mercados, informais e ilícitos, como um outro mercado, um mercado político, também ilegal, que passa por dentro dos aparatos legais oficiais e nos quais são transacionadas as mercadorias políticas (acordos, suborno, compra de proteção, corrupção) dos quais dependem o funcionamento desses mercados e que são constitutivos de seus modos de regulação.

Nas páginas que seguem, gostaria de retomar e desdobrar algumas dessas questões na tentativa de avançar o que pode ser entendido como pistas e hipóteses de trabalho a serem experimentadas em nossas pesquisas. 
A discussão que se segue organiza-se em torno de duas ordens de questões:

Primeiro ponto: os campos de força que se estruturam nas dobras do legal e ilegal. Isso me parece importante para conferir estatuto (e tirar consequências) à dinâmica dos conflitos, disputas e tensões que se armam nesses pontos de fricção com as forças da lei e da ordem, no jogo oscilante de práticas que transitam entre tolerância, formas de negociação, dispositivos de controle e repressão. É por esse prisma que se pode dizer que nesses campos de força se processa uma disputa pelos sentidos de ordem e seu inverso, bem como dos critérios de legitimidade dos ordenamentos sociais que vêm se engendrando nas fronteiras incertas - em disputa - do legal e legal. Essa é uma hipótese lançada em textos anteriores (Kessler e Telles, 2010a; Telles e Hirata, 2010; Telles, 2010) e que eu gostaria de retrabalhar nas páginas que se seguem. Ainda: o lugar estratégico da transação das mercadorias políticas na interface desses mercados com os poderes públicos nos permite avançar uma segunda hipótese: são jogos de poder que se fazem nos pontos em que se entrelaçam as redes urbanas de circulação de riquezas e as redes de poder em disputa em torno dos modos de apropriação dessa riqueza circulante. É isso o que parece estar em pauta nos conflitos e disputas instalados nos meandros urbanos do comércio informal e ilegal.

Segundo ponto: o estatuto e o lugar das etnografias desses mercados, informais e ilegais. Já aviso, de partida, que não se pretende entrar aqui na espinhosa polêmica, cara aos antropólogos, sobre a escrita etnográfica. Tampouco se pretende enfrentar a também espinhosa discussão sobre os desafios teórico-metodológicos postos pelas dinâmicas transnacionais que redefinem por inteiro o campo empírico do trabalho etnográfico. Essas são questões importantes, mas sua discussão ficará para outro momento. Aqui, o ponto é outro e diz respeito ao conhecimento que se pode produzir na descrição desses agenciamentos políticos, que nos interessa aqui bem entender. Na verdade, é uma terceira hipótese que eu gostaria de experimentar, uma hipótese teórico-metodológica que diz respeito ao modo de tratar a presença (e lugar) do estado e dos dispositivos legais nesses mercados e que remete ao que alguns autores vêm propondo nos termos de uma antropologia do Estado visto pelo ângulo de suas práticas em contextos situados ou, como propõem Das e Poole (2004), a partir de suas "margens". Nesse plano, a etnografia desses mercados desdobra-se em uma etnografia política, colocando em mira os jogos de poder e relações de força que se processam nesses campos de disputa. Por essa via, podemos entender algo das dimensões políticas envolvidas nesses mercados. 


\section{Fronteiras da lei como campo de disputas}

Antes de mais nada, será preciso se deter sobre essa transitividade entre o formal e o informal, legal e ilegal, e também o ilícito, que está no centro das dinâmicas urbanas de nossas cidades. De partida, vale dizer que se trata de uma trama intrincada de relações que torna inviável sustentar definições fixas, categoriais e normativas dessas categorias. De um lado, ao longo das rotas transnacionais dos circuitos informais, os produtos passam, como bem nota Rosana Pinheiro-Machado (2008), por verdadeiras metamorfoses legais, na própria medida em que os códigos formais e parâmetros legais variam de um país a outro, como também varia o grau de tolerância das autoridades locais em relação a essas práticas mercantis. Por outro lado, a etnografia desses mercados mostra uma composição variada de procedimentos e expedientes formais e informais, legais e ilegais postos em ação para a circulação e transação desses produtos: as mercadorias podem ter uma origem formal legal, chegando ao consumidor pelas vias das práticas do comércio de rua, da fraude fiscal nas lojas em que são negociadas, passando (ou não) pelos trajetos do "contrabando de formiga" nas regiões de fronteira ou, então, pelos trajetos mais obscuros e mais pesados dos empresários dos negócios ilegais que agenciam o contrabando dos produtos que chegam pelos contêineres desembarcados nos principais portos do país (cf. Freire, 2012). Os atores também transitam de um lado e de outro das fronteiras porosas do legal e do ilegal: ambulantes em situação regularizada pela Prefeitura, mas que se abastecem de produtos de origem incerta, quase sempre indiscernível (contrabando, falsificações, "desvio"); pequenos comerciantes envolvidos nos negócios do contrabando, mas que cuidam de respeitar (na medida do possível) os códigos legais na montagem de seus negócios. Ainda: migrantes bolivianos em situação regularizada e que estão à frente (patrões) de confecções de produtos falsificados, infringindo ao mesmo tempo códigos da legislação do trabalho, além do emprego de migrantes em situação irregular (conterrâneos e outros, como os paraguaios), tudo isso se compondo (mas nem sempre), sob modulações variadas, em uma nebulosa de situações incertas entre o legal e o ilegal que acompanham as extensas redes de subcontratação vinculadas ao poderoso e globalizado circuito da moda e das grifes famosas (Côrtes, 2013). Também: empresários chineses bem estabelecidos, migração mais antiga, situação regularizada e de posse de títulos da cidadania brasileira e que, como mostra a pesquisa de Douglas Toledo Piza (2012), fazem uso dos recursos legais de que dispõem para se 
lançar nos nebulosos negócios de importação (quer dizer: contrabando) e os negócios imobiliários, também nebulosos, vinculados às galerias que se multiplicaram nos últimos anos nos centros do comércio popular em São Paulo.

Quanto aos mercados de bens ilícitos, essa transitividade entre o formal e o informal, legal e ilegal, processa-se nos meandros da "economia de bazar" que hoje se instala no coração dinâmico das economias urbanas. É questão que também aparece nas filigranas das etnografias desses mercados: uma superposição de atividades informais e ilegais na qual os fluxos de dinheiro, de mercadorias, de bens de origem ilícita e também as drogas se entrecruzam em um complexo sistema de trocas, se inscrevem no jogo das relações sociais e passam a compor as dinâmicas urbanas que transbordam amplamente o perímetro dos territórios da pobreza. Mesmo quando se considera as atividades inequivocamente criminosas (quer dizer: sujeitas aos processos de incriminação), como é o caso dos pontos de venda de droga em um bairro de periferia, as situações perdem a nitidez suposta nessas formas de tipificação quando seguimos os traços dos percursos de bens e pessoas nas dinâmicas locais e do entorno imediato. Assim, por exemplo, na região em que fazemos nossas pesquisas, temos o exemplo do traficante local, patrão da "biqueira" instalada no bairro e que, preocupado com o seu futuro e o de sua família, trata de abrir um pequeno empreendimento no entorno próximo, uma loja de roupas ou, então, no caso de um gerente desse mesmo ponto de droga, uma lan-house intensamente frequentada pelos jovens da região. Um e outro, com a expertise própria dos que sabem lidar com os meandros das atividades ilegais, tratam de se precaver e evitar complicações com fiscais da Prefeitura, de tal modo que seus empreendimentos, na contramaré do que acontece em todos os lugares, são mais do que legais - produtos comprados em lojas, com nota fiscal, nada pirateado, nada falsificado, tudo comprovado e tudo muito bem documentado em registros formais legais. Ao mesmo tempo em que se tornam pequenos empreendedores locais, são eles, junto com outros tantos de seus parceiros nos negócios ilícitos, que fazem circular algo como os "excedentes" dos negócios da droga ao promover melhorias nos campos de várzea, distribuir cestas básicas, organizar festas juninas e, não poucas vezes, fazer a mediação e a negociação com órgãos da Prefeitura responsáveis por esses assuntos locais. A descrição dessas situações já foi feita em outras ocasiões e não é o caso de retomá-las (cf. Telles e Hirata, 2007, 2010; Telles, 2009, 2010; Hirata, 2010).

Poderíamos multiplicar os exemplos. Por ora, importa salientar essa multiplicidade e heterogeneidade interna às situações de formalidade ou legalidade, tanto 
quanto às situações informais e ilegais. Esta é a primeira questão a ser destacada: as fronteiras do legal e do ilegal não são lineares, muito menos dicotômicas. Dispositivos (e práticas) formais e informais, legais e ilegais, operam como agenciamentos práticos, situados, fazendo a combinação de recursos e repertórios de um lado e de outro; algo como marcadores e pontos de referência que fazem o traçado de territórios rizomáticos transpassados por redes superpostas de coisas e pessoas, transversais às várias situações de vida e trabalho e que se desdobram em outras tantas situações e outras tantas teias de relações situadas em outros contextos próximos ou superpostos (cf. Chauvin, 2009; Fischer e Spire, 2009; Heyman, 1999).

No entanto, se há porosidade nas fronteiras do legal e do ilegal, formal e informal, nem por isso a passagem de um lado a outro é coisa simples. Esse é o segundo ponto a ser discutido, o mais importante: leis e códigos formais têm efeitos de poder e condicionam o modo como esses mercados e essas atividades se estruturam. Circunscrevem campos de força e é em relação a eles que essa transitividade de pessoas, bens e mercadorias precisa ser bem situada. E, a rigor, descrita. São campos de força que se deslocam, se redefinem e se refazem conforme a vigência de formas variadas de controle e também, ou sobretudo, os critérios e procedimentos de incriminação dessas práticas e dessas atividades, oscilando entre a tolerância, a transgressão consentida e a repressão.

Essas fronteiras, portanto, são politicamente sensíveis. E circunscrevem campos de disputa em que se combinam e se alternam a negociação, formas de controle, tolerância e repressão. É por esse prisma que se pode dizer que nesses campos de força se processa uma disputa surda ou aberta sobre os sentidos de ordem e o seu inverso, bem como dos critérios de legitimidade dos ordenamentos sociais (também em disputa) que vêm se engendrando nessas fronteiras incertas.

$$
* \quad * \quad *
$$

Se é verdade que essa transitividade entre o legal e ilegal, entre o formal e informal vem sendo flagrada em inúmeras pesquisas e está no cerne das questões discutidas por vários autores, também é verdade que as dimensões políticas dessas práticas e dessas atividades nem sempre são problematizadas. E é isso que será preciso entender. $\mathrm{O}$ fato é que se há porosidade nas fronteiras do legal e ilegal, formal e informal, nem por isso a passagem de um lado a outro é coisa simples. Esse o ponto a ser discutido: leis e códigos formais têm efeitos de poder e condicionam o modo como esses mercados e essas atividades se estruturam. Circunscre- 
vem campos de força e é em relação a eles que essa transitividade de pessoas, bens e mercadorias precisa ser situada. E, a rigor, descrita. São campos de força que se deslocam, se redefinem e se refazem conforme a vigência de formas variadas de controle e também, ou sobretudo, os critérios e procedimentos de incriminação dessas práticas e dessas atividades, oscilando entre a tolerância, a transgressão consentida e a repressão conforme contextos, microconjunturas políticas e as relações de poder que se configuram em cada qual.

Essas fronteiras, portanto, são politicamente sensíveis. E isso significa dizer que será importante colocar no foco da análise justamente os jogos de poder que se processam nas dobras do legal e ilegal, do formal e informal. É por esse prisma que se pode dizer que nesses campos de força se processa uma disputa surda ou aberta sobre os sentidos de ordem e o seu inverso, bem como dos critérios de legitimidade dos ordenamentos sociais (também em disputa) que vêm se engendrando nessas fronteiras incertas.

$$
* \quad * \quad *
$$

Para bem situar essas questões, permito-me lançar mão de uma situação trabalhada por Maria Pita (2012) em Buenos Aires: é uma situação que nos interessa, pois, no conflito aberto em torno dos ambulantes senegaleses, é possível apreender o que parece estar em jogo nos campos de disputa que se armam nos centros de comércio popular em São Paulo, quiçá em outros lugares. Migrantes recentes, em sua maioria em situação irregular, desenvolviam um comércio de rua interditado pelos códigos urbanos nos locais em que se instalaram. As denúncias se multiplicaram: maus-tratos por parte das forças policiais, violência, abuso de poder, discriminação racial, além da expropriação de bens e ganhos obtidos com o comércio informal. Também, o mais importante: o escândalo da diferença de tratamento em relação a outros ambulantes, com os quais prevaleciam os arreglos e transações em troca da garantia de não serem molestados. A situação terminou por mobilizar advogados ativistas dos direitos humanos e desdobrou-se nas instâncias judiciais para resolver um litígio, no qual estavam em jogo os modos de aplicação da lei e os modos de operação das forças da ordem. Este é o ponto que me interessa frisar: nas cenas descritas por Maria Pita, os sinais do legal e ilegal se invertem, colocando em foco as irregularidades, quando não a ilegalidade dos modos de operação das forças da ordem. Quer dizer: os arreglos e a compra de proteção para uns; a violência extralegal para os outros, os senegaleses. Quanto a esses, a suposta ilegali- 
dade de suas atividades também foi colocada em questão em uma disputa de interpretação da própria lei, dadas as ambivalências dos códigos urbanos que abriam brechas pelas quais as atividades de sobrevivência que eles desenvolviam não poderiam ser tipificadas como ilegais, nem crime, nem contravenção. No final, a solução não foi favorável aos senegaleses: em nome da lei e da ordem, os poderes de polícia foram reafirmados como modo de gestão e regulação desses territórios. Muito concretamente, esse o outro ponto a ser enfatizado: o seu poder de aplicar — ou não aplicar - a lei, sob a lógica própria de seu poder discricionário, autorizando uns e interditando outros, tipificando os delitos de uns e outros (crime, contravenção), abrindo a uns (e não a outros) o ambivalente jogo de acordos, entre chantagem e compra de proteção em troca da não aplicação da lei.

Essa cena aberta em torno dos senegaleses em Buenos Aires nos oferece, em filigrana, o que parece estar contido nos campos de força estruturados nos mercados informais de São Paulo. Assim, por exemplo: para contornar as formalidades legais e ampliar o raio de ação no combate à pirataria, as forças policiais não hesitam em lançar mão de outros modos de tipificação legal: crime contra as relações de consumo; sonegação fiscal ou formação de quadrilhas (quer dizer: enquadramento na definição de crime organizado). Ou, então, por desacato à autoridade no caso dos incautos que não acatarem a voz de comando da Polícia Militar, que hoje está à frente de um aberto e ofensivo "combate" aos ambulantes "irregulares", por conta de um muito controvertido acordo da Prefeitura de São Paulo e o governo do Estado, a chamada “Operação Delegada": a rigor, como diz Daniel Hirata (2012), uma "gambiarra jurídica" que suspende as circunscrições legais que definem as atribuições da Polícia Militar, de modo a ampliar o seu espaço de atuação nesse terreno em que as funções de fiscalização e controle eram de responsabilidade de outras instâncias políticas (fiscais da Prefeitura) e outros órgãos de polícia. Sob a lógica muito moderna e muito contemporânea das "tecnologias securitárias como modo de gestão do espaço urbano" (Hirata, 2012), processa-se a simbiose entre ordem pública e segurança urbana. Na prática, como enfatiza Hirata, uma legislação de exceção que amplia os poderes discricionários da polícia na execução dessas operações, alterando as formas de controle e os modos de incriminação das transgressões legais ou irregularidades urbanas do comércio de rua.

Trata-se, certamente, de um endurecimento das formas de controle. Mas é também importante notar o modo como as forças da ordem operam. É nesse plano miúdo e cotidiano que se pode flagrar o poder discricionário de que dispõem as forças policiais nos modos de aplicar (ou não aplicar) a lei e que se duplica e se 
amplia na própria medida da imprecisão inscrita nos códigos legais, ainda mais quando se referem a situações também elas muito embaralhadas e intrincadas quanto ao estatuto das atividades desenvolvidas. Mas é nesse terreno que entram em cena práticas nebulosas que oscilam entre acordos, corrupção, troca de favores, compra de proteção - enfim, a transação das mercadorias políticas, sempre no limiar da chantagem, da extorsão e também dos usos da violência extralegal.

Como mostra Carlos Freire (2012), esses dispositivos de controle acompanham programas de intervenção urbana que redefinem regras, critérios e procedimentos para a distribuição e a ocupação do comércio de rua nesses espaços, bem como a atribuição de garantias a uns, a suspensão de autorização a outros ou, então, a interdição das atividades a outros tantos. Ao mesmo tempo, novos dispositivos jurídicos são colocados em ação, como exigência para a formalização dessas atividades, introduzindo novas clivagens, as quais, na prática, deslocam e redefinem as próprias fronteiras do que é considerado formal e informal, legal e ilegal. Na fina etnografia que Carlos Freire faz das mutações recentes desses mercados, as regulações estatais postas em operação poderiam ser vistas como "um conjunto de táticas que recriam a informalidade, transformando-a em governamentalidade" (Alsayyad e Roy, 2009), táticas que combinam dispositivos políticos-jurídicos (promoção do chamado empreendedorismo, conversão dos ambulantes em microempreendedores), o uso da coerção para impor as novas regras do jogo e a repressão aberta, quando não o uso da violência extralegal justificada em nome do "combate à pirataria" e a "guerra ao crime" agora associado ao comércio de rua nesses lugares. Há toda uma cartografia política do comércio que se redefine, cujos contornos são cambiantes tanto quanto as regras - em disputa - que regem o acesso e o funcionamento desses mercados, ao mesmo tempo em que há legião de ambulantes que, desprovidos do "credenciais" de reconhecimento, são expulsos, sujeitos às formas mais agressivas de controle e repressão, espalhando-se por outros cantos da cidade.

Essa conjugação entre formas de intervenção urbana e dispositivos de controle terminaram por estruturar um acirrado campo de disputa justamente em torno das regras de ocupação desses espaços. Regras cambiantes e incertas quanto aos critérios que autorizam uns e não outros para o exercício de suas atividades e que definem sua distribuição entre os lugares mais valorizados e os que ficam nas suas fímbrias. Campos de tensão e de conflito que também se estruturam em torno das taxas cobradas de uns e outros para o exercício das atividades; taxas de legalidade duvidosa em alguns casos, de legitimidade contestada em outros, até porque é tudo mesmo muito nebuloso: nunca se sabe ao certo se são dispositivos legais ou, então, 
formas quase institucionalizadas dos mercados de proteção ou acordos mafiosos com as autoridades informais que fazem a gestão desses espaços ou, ainda, os meandros intrincados da corrupção, mobilizando atores e suas redes de relações: empresários dos negócios ilegais, forças policiais, políticos e suas máquinas partidárias, gestores urbanos, funcionários de agências estatais, também empresas privadas envolvidas nos chamados projetos de recuperação urbana da região e nas quais não faltam conexões transnacionais (fontes de financiamento, acionistas, consultores). Nos meandros dessa cadeia de relações, processam-se os agenciamentos políticos igualmente nebulosos, acordos e negociações, conflitos, disputas e, muito frequentemente, histórias de morte.

Tudo isso é matéria da fina etnografia desses mercados que os autores aqui citados nos entregam. Por ora, essas rápidas (e incompletas) indicações são aqui lançadas pelas questões que suscitam. Esses dois exemplos, ou melhor, essas duas cenas urbanas, senegaleses em Buenos Aires, ambulantes em São Paulo, fazem ver os modos operantes da lei e dos códigos formais, melhor dizendo: as práticas e os agenciamentos situados pelos quais a presença do Estado deixa suas marcas impressas na cartografia cambiante desses territórios. Nos termos de Veena Das (2007), "assinaturas do Estado" impressas no modo como códigos, normas, leis circulam, são agenciados, negociados, postos em ação nos contextos situados desses territórios, redefinindo a distribuição do permitido, do tolerado e do reprimido, bem como o jogo oscilante entre a repressão e os acordos negociados, entre o legal e o extralegal. Altera-se a cartografia política, tanto quanto a distribuição dos lugares, das posições, das hierarquias na ocupação desses espaços. É importante notar que as "assinaturas do Estado" são o registro da presença do Estado, a sua face legal-burocrática, com diz a autora, incorporada nas regras e regulações desses espaços e dessas atividades, nos seus dispositivos, agentes e procedimentos pelos quais elas se efetivam, operando como uma "força gravitacional" das práticas e modos como os atores lidam com a situação, e seus pontos de fricção, os recursos mobilizados para contornar, resistir, enfrentar e, no final das contas, sobreviver nesses lugares (Das, 2007).

No caso dos mercados de bens ilícitos, Gabriel Feltran (2012) nos entrega outras tantas situações que nos ajudam a pensar essas questões. Nas três "situações etnográficas" trabalhadas por Feltran em um bairro da periferia da cidade de São Paulo, as "assinaturas do Estado" também circulam no modo como "crime" e "criminosos", "trabalhadores" e "bandidos" são qualificados (ou não) como tais no jogo interativo (e conflitivo) com a polícia no uso de seu poder discricionário 
para aplicar (flagrante, prisão) ou não a lei (acordos, transações). Mas as "assinaturas do estado" também circulam conforme as "credenciais" dos indivíduos envolvidos e que condicionam o modo como a polícia arbitra essas situações, quer dizer, condicionam os jogos estratégicos de poder nesses contextos situados: seja a situação legal dos indivíduos - menores de idade e, portanto, amparados pelo Estatuto da Criança e do Adolescente, garotos em situação de "liberdade assistida", sob tutela de entidades sociais locais ou, então, ex-presidiários e indivíduos em situação de liberdade condicional e que, por isso mesmo, tentam por todas as vias contornar o flagrante (operação de registro legal) e a volta à prisão -; seja o modo como uns e outros se situam no interior do "mundo do crime": o preço do acordo varia conforme a posição do indivíduo no mercado local de drogas e conforme sua importância no interior da organização criminosa que controla os negócios ilícitos na região; seja, finalmente, no modo como os acordos são feitos (ou não) conforme essas credenciais (legais e não legais) e a rede de relações que uns e outros são capazes de mobilizar: a família e seus "conhecimentos" no mundo do crime e nas esferas legais, a polícia, delegados e advogados que operam a transação entre a lei e o "crime", grupos criminosos que arcam (ou não) com os custos dos acordos e que se declinam conforme os protocolos de suas relações com as forças da ordem e da lei.

Colocadas lado a lado, essas microcenas que pontuam os mercados informais e os mercados de bens ilícitos fazem ver os modos operantes da gestão diferencial dos ilegalismos - algo que faz parte dos modos de funcionamento do poder. ${ }^{1} \mathrm{E}$ importante reter a questão: a noção de gestão diferencial dos ilegalismos define um plano conceitual que permite situar o lugar da lei e dos dispositivos formais não como referência normativa, mas como locus de ajustamentos variáveis das relações de poder nos meandros desses mercados e dessas atividades das quais estamos aqui tratando (Peralva, 2010; Telles, 2010). E isso tem consequências que seria preciso explorar.

Primeiro: é esse um espaço conceitual que nos permite situar e conferir estatuto a práticas e agenciamentos políticos que se fazem nas dobras do legal e do

1. Ao cunhar essa noção, Foucault desloca a discussão da tautológica e estéril binaridade legal-ilegal, para colocar no centro da investigação os modos como as leis operam, não para coibir ou suprimir os ilegalismos, mas para diferenciá-los internamente, "riscar os limites de tolerância, dar terreno para alguns, fazer pressão sobre outros, excluir uma parte, tornar útil outra, neutralizar estes, tirar proveito daqueles (Foucault, 1997, p. 227). A noção de ilegalismos e gestão diferencial de ilegalismos foi tratada por mim em trabalhos anteriores. Cf. Telles, 2009, 2010. 
ilegal. As leis, diz Foucault, "não são feitas para impedir tal ou qual comportamento, mas para diferenciar as maneiras de contornar a própria lei" (Foucault, 1994, p. 716). Mas é justamente nesses torneios da lei que as questões se configuram. É isso o que está aqui sendo visado ao se chamar a atenção para o que acontece nas dobras do legal-ilegal.

Segundo: as microcenas rapidamente indicadas nas páginas anteriores também fazem ver que a gestão diferencial dos ilegalismos se processa em contextos situados. E é por referência a essa dimensão contextual que se pode apreender os campos de força e de disputa que se instauram em torno dessas fricções com a lei e o Estado, não como entidades formais abstratas, mas na lógica de seus modos de operação nesses terrenos que se tecem em torno dos modos incertos e diferenciados de aplicação (ou não aplicação) da lei. É aí que se instauram campos de força que colocam em cena uma meada de atores distribuídos nas posições e hierarquias que conformam a cartografia cambiante desses territórios. É o terreno do arbítrio, do uso da violência e dos dispositivos de exceção constitutivos dos modos operantes, práticos, da lei e das forças da ordem. Mas é esse também o campo de negociações, acordos, disputas entre os atores envolvidos, também eles transitando entre dispositivos legais e ilegais.

Terceiro: nesses contextos situados, matéria da etnografia fina desses mercados e dessas atividades, é que se pode apreender a face política dessa trama de práticas informais e ilegais, na sua interface com as forças da lei e os dispositivos políticos, também jurídicos, que circunscrevem, para usar os termos de Fischer e Spire (2009), as arenas da gestão dos ilegalismos. É isso que será preciso ainda bem entender e, por essa via, conferir estatuto - político, teórico — aos conflitos e disputas inscritos nesses pontos de fricção com a lei e que acompanham a expansão dos ilegalismos nas tramas urbanas.

\section{Antropologia do Estado: apontamentos}

Se é importante entender o lugar do Estado e da lei nesses ordenamentos, isso nos coloca uma questão de ordem teórico-metodológica: de partida, será preciso se desvencilhar das "imagens verticais" do Estado (Ferguson e Gupta, 2002; Gupta, 2006) e das definições normativas da lei e do direito. Quer dizer: o Estado e as leis tomados como entidades unitárias (ou típico-ideais), pressuposto 
e axioma a partir do qual tudo o que ocorre no plano das práticas efetivas aparece no registro da falta, da falha ou, então, no caso de nossas sociedades, das "heranças malditas" legadas por uma história de longa duração (Das e Poole, 2004). Exigência, portanto, de um deslocamento de perspectivas para perscrutar as relações de poder tal como elas se processam nos contextos situados de tempo e de espaço (Misse, 2006, 2009).

Mais ainda: exigência de um deslocamento de perspectiva para dar conta das redefinições dos jogos de poder nesses pontos de inflexão do mundo contemporâneo e bem situar as interrogações (outras perguntas) acerca dos ordenamentos sociais que vêm se desenhando nas últimas décadas. Como dizem Das e Poole (2004), é o caso de se perguntar pela relação entre práticas extralegais e os modos de funcionamento do Estado, algo que se instala no interior de suas funções de ordenamento. É isso, dizem as autoras, que pode nos dar uma chave para entender a própria produção da ordem, rastreando os modos de operação dos dispositivos legais e das agências estatais, seus tempos, seus procedimentos, suas técnicas e tecnologias de ação, em contextos situados no tempo e no espaço. Mais ainda e mais fundamentalmente: em vez de partir da imagem consolidada do Estado como entidade política e administrativa que tende a se debilitar ou a se desarticular nas suas margens territoriais e sociais (os confins do Estado, vistos como zonas sem lei, territórios do não direito), é o caso de deslocar o campo a partir do qual as questões podem ser formuladas. Pois é o Estado que produz essas "margens" e, sendo assim, trata-se, então, de rastrear o modo como "as práticas e políticas da vida nessas áreas modelam as práticas políticas de regulação e disciplinamento que constituem aquilo a que chamamos "o Estado" (Das e Poole, 2004, p. 3). São nessas margens que "o Estado está constantemente redefinindo seus modos de governar e legislar", justamente nesses pontos de fricção com práticas e outras formas de regulação inscritas nas tramas da vida nesses lugares.

No centro dos debates contemporâneos, essas são, certamente, questões de fronteira, aqui apenas muito rápida e toscamente indicadas. Nos limites destas páginas, vale dizer e enfatizar: é nesse plano que o exercício etnográfico ganha toda a sua importância para perscrutar os agenciamentos práticos dos dispositivos políticos postos em ação, suas técnicas, protocolos e modos de operação. Não por acaso, os autores aqui citados (e outros) chamam a atenção justamente para isso: a importância de uma antropologia do Estado. Na formulação de Das e Poole (2004), trata-se de tomar como perspectiva o que acontece nas suas "margens" e, por essa via, entender a mecânica de funcionamento do próprio Estado ao rastrear as relações 
que articulam internamente lei e exceção, direito e "vida nua". Na versão de Fischer e Spire (2009), o ponto de mira são as arenas de gestão diferencial dos ilegalismos, que permitem rastrear as redefinições e deslocamentos da lei e do direito (e do lugar da lei e do direito) que acompanham o atual recentramento das atividades do Estado e seus operadores em torno dos dispositivos de governamentalidade (quer dizer, gestão das populações). Na proposta de Heymna e Smart (1999), trata-se de colocar em foco as práticas e processos (e não regras e estruturas) e, por essa via, entender os nexos que articulam o Estado e práticas ilegais, que perpassam os modos de operação de suas agências, suas instâncias e seus postos burocráticos, e que podem abrir um caminho para o entendimento dos modos de formação e a mecânica de funcionamento das leis e do Estado. É sob essa perspectiva, dizem os autores, que é possível se desvencilhar do cânone que postula o Estado como entidade unitária e portador de uma única racionalidade. O Estado não é uma invenção da lei e da ordem, dizem os autores, mas uma rede complexa do legal e do ilegal: as leis criam inevitavelmente a sua contrapartida, zonas de ambiguidade e de ilegalidade, que criam por sua vez todo um campo de práticas e agenciamentos que se ramificam por vários lados, também mercados alternativos e oportunidades para bens e serviços ilegais.

Esses autores, cada qual partindo de suas respectivas chaves teóricas e campos de problematização, tratam de colocar no foco do trabalho etnográfico os nexos que articulam Estado e práticas ilegais, regulações estatais e não estatais, o formal e o que escapa às suas codificações. Transversal a todas essas questões está uma indagação de fundo sobre os processos pelos quais Estado, leis e ordem se constituem e como operam em contextos situados. Esse é um registro interessante para se apreender o sentido das transformações que abalaram, nos últimos tempos, justamente as relações entre Estado, economia e sociedade, de tal forma que essas categorias (Estado, leis, ordem) perdem sua autoevidência como referência normativa e axioma não refletido das categorias cognitivas (e normativas) das ciências sociais. E é justamente nesses deslocamentos que, em vez do uso normativo e pré-codificado dessas categorias, estas assinalam o lugar de uma questão, questão política, também questão ou questões de pesquisa — que precisa ser problematizado.

Essa é uma discussão de fundo, que vai além do que se pretende e se tem condições de fazer nos limites destas páginas. Mas é importante reter essas questões, pois elas ajudam a qualificar o campo de disputa que se estrutura nessas fronteiras incertas, também elas em disputa, do formal e informal, do legal e 
ilegal. No que diz respeito aos mercados informais, seria possível dizer que, nas filigranas das cenas descritivas comentadas páginas atrás, parece se explicitar um campo de disputas em que as próprias fronteiras da economia estão se redefinindo nos meandros, também em disputa, desses mercados: campos de força e de disputa que se estruturam em torno das regras e critérios que introduzem novas clivagens, definem a cartografia política, sempre cambiante, desses lugares e regem o acesso (e bloqueios) a esses mercados; disputas em torno dos modos legais e extralegais de regulação desses mercados; disputas em torno dos meios legais e extralegais de apropriação da riqueza circulante; disputas em torno dos critérios de ordem e seu avesso. Seguindo Beatrice Hibou (1998), em outro contexto de discussão, mas com fortes ressonâncias com o que se está aqui discutindo, a incerteza quanto às fronteiras do legal e ilegal, bem como das regras do jogo nesses campos de disputa, é também uma forma de governo e um instrumento de poder. Mas, então, seria possível desdobrar a questão pois fica a sugestão de que se trata de "modos de governar as fronteiras de criação de riquezas", para usar os termos de Jannet Roitman (2004), em um texto no qual essas linhas estão fortemente inspiradas.

No coração de nossas cidades (e outras), esses mercados podem ser tomados como "fronteiras analíticas", para usar a expressão de Saskia Sassen (2008), em que as regras e os jogos de poder estão se redefinindo. Mas é por isso mesmo que são um lócus privilegiado para entender os nexos que articulam lei e exceção, direito e violência, contratos e força no próprio modo como os mercados são produzidos. É em torno desses nexos que se estruturam os campos de força contidos nos modos como ordenamentos sociais se fazem nas fronteiras incertas do legal e do ilegal. Nas microcenas que pontilham esses mercados, temos as pistas para entender o modo como os ordenamentos sociais são fabricados, engendrados em um campo de disputa que desloca, faz e refaz a demarcação entre a lei e o extralegal, entre justiça e força, entre acordos pactuados e a violência, entre a ordem e seu avesso. Também os limites do tolerável e intolerável, esse ponto que estala nas formas abertas de conflito e que também se pode ouvir nos "rumores da multidão" (Thompson).

Recebido em 14/6/2013 - Aprovado em 20/6/2013 


\section{Referências bibliográficas}

ALSALYYAD, N.; ROY, A. Modernidade medieval. Novos Estudos, São Paulo, p. 1-26, 26 nov. 2009.

CHAUVIN, S. En attendant les papiers. Politix, Paris, v. 87, n. 3, p. 47, 2009.

CORTÊS, T. A migração da cultura e o trabalho escravo. Dissertação (Mestrado) - Universidade de São Paulo, São Paulo, 2013.

DAS, V. The signature of the State. In: Life and words. California: University of California Press, 2007. p. 162-183.

; POOLE, V. (Eds.). Anthropology in the margins of the state. Santa Fe: School of American Research Press, 2004.

DETIENNE, M.; VERNANT, J. P. Les ruses de l'Intelligence: le métis des Grecs. Paris: Flammarion, 1974.

FELTRAN, Gabriel. Manter a ordem na periferia de São Paulo: coexistência de dispositivos normativos na "era PCC". In: AZAIS, Christian; KESSLER, Gabriel; TELLES, Vera S. Ilegalismos, cidade e política. Belo Horizonte: Fino Traço, 2012. p. 253-279.

FERGUSON, James; GUPTA, Akhil. Spatializing States: toward an ethnography of neoliberal governmentality, American Ethnologist, v. 29, n. 4, p. 981-1002, 2002.

FISCHER, N.; SPIRE, A. L’État face aux illégalismes. Politix, Paris, v. 87, n. 3, p. 7, 2009.

FOUCAULT, Michel. Des súplices aux cellules. Dits et Écrits II. Paris, Gallimard, p. 716-720, 1994.

. Vigiar e punir. Nascimento da prisão. Petrópolis: Vozes, 1997.

FREIRE, Carlos. Mercado informal e Estado: jogos de poder entre tolerância e repressão. In: AZAÏS, C.; KESSLER, G.; TELLES, V. S. Ilegalismos, cidade e política. Belo Horizonte: Fino Traço, 2012. p. 57-80.

GUPTA, A. Blurred boundaries: the discourse of corruption, the culture of politics and the imagined state. In: GUPTA, Akhil; SHARMA, Aradhana. The anthropology of the State: a reader. Blackwel Plublishing, 2008. p. 211-242.

HIBOU, B. Retrait ou redéploiement de l'Etat? Critique Internationale, Paris, v. 1, n. 1, p. 151-168, 1998.

HIRATA, D. V. A produção das cidades securitárias: polícia e política. Le Monde Diplomatique Brasil, São Paulo, p. 1-3, 11 jun. 2012. 
HIRATA, D. V. Sobreviver na adversidade: entre o mercado e a vida. Tese (Doutorado) — Universidade de São Paulo, São Paulo, 12 jul. 2010.

HEYMAN, J. (Ed.). States and illegal practices. Chicago: Berg Editorial, 1999.

MCC HEYMAN, J. Risque et confiance dans le contrôle des frontières américaines. Politix, Paris, v. 87, n. 3, p. 21-30, 2009.

MISSE, M. Crime e violência no Brasil contemporâneo. Rio de Janeiro: Lumen Juris, 2006. Trocas ilícitas e mercadorias políticas. Anuário Antropológico, v. 2, p. 89-107, 2009.

PERALVA, Angelina. Prefácio. In: TELLES, Vera. S. A cidade nas fronteiras do legal e ilegal. Belo Horizonte: Argvmentvm, 2010.

PITA, Maria V. Poder de polícia e gestão de territórios: o caso dos ambulantes senegaleses na Cidade Autonoma de Buenos Aires. In: AZAÏS, C.; KESSLER, G.; TELLES, V. S. Ilegalismos, cidade e politica. Belo Horizonte: Fino Traço, 2012.

PIZA, D. T. Tramas relacionais de migrantes chineses e comércio informal. Dissertação (Mestrado) — Universidade de São Paulo, São Paulo, 2012.

ROITMAN, Jannet. Produtivity in de margins: the reconstitution of the state power in the Chad Basin. In: DAS, V.; POOLE, D. Anthropology in de margins of de State. Santa Fe: School of American Research, 2005.

RUGGIERO, V.; SOUTH, N. The late-modern city as a bazaar. The British Jounal of Sociology, London, v. 48, n. 1, p. 54-70, 18 mar. 1997.

SASSEN, S. Territory, authority, rights. Nova Jersey: Princeton University Press, 2008.

TELLES, V. S. Nas dobras do legal e ilegal: ilegalismos e jogos de poder nas tramas da cidade. Dilemas, revista de estudos de conflitos e controle social, Rio de Janeiro, v. 2, n. 5-6, p. $97-126,28$ out. 2010 a.

. A cidade nas fronteiras do legal e ilegal. Belo Horizonte: Fino Traço, 2010b.

; HIRATA, D. V. Cidade e práticas urbanas: nas fronteiras incertas do legal e ilegal. Estudos Avançados, São Paulo, v. 21, n. 61, p. 173-191, 31 out. 2007.

. Ilegalismos e jogos de poder em São Paulo. Tempo Social, Revista de Sociologia da USP, São Paulo, v. 22, n. 2, p. 39-59, 4 nov. 2010.

; KESSLER, G. Ilegalismos na América Latina. Tempo Social, revista de sociologia da Universidade de São Paulo, São Paulo. v. 22, n. 2, p. 9-16, 27 fev. 2010a.

THOMPSON, E. P. Tradición, revuelta y consciencia de clase: estudios sobre la crisis de la sociedad preindustrial. Barcelona: Editorial Critica, 1979. 